\title{
The Effect of Holy Quran Recitation on Clinical Outcomes of Patients Undergoing Weaning from Mechanical Ventilation
}

\author{
Nermine M. Elcokany ", Mona Saad Abd El Wareth \\ Alexandria University, Faculty of Nursing, 9 Edmon fermon St., Smouha, Alexandria \\ *Corresponding Author: Nermine M. Elcokany; n.elcokany@email.com
}

Received 01 July 2019;

Accepted 21 July 2019;

Published 30 July 2019

\begin{abstract}
Background: Mechanically ventilated patients experience many stressors related to their physiological conditions, treatments, and the Intensive Care Unit (ICU) environment itself. As patients are recovered from the respiratory problems, they can be weaned from mechanical ventilation (MV). Weaning represents a major challenge in critically ill patients' management. Weaning from MV imposes more stress on the patients as it leads to feeling of helplessness. Excessive and inappropriate use of sedatives can result in cardiovascular instability, prolongation of MV and ventilator associated pneumonia. Critical care nurses have an important role in alleviating stress manifestations and helping patients' holistic healing. Non-pharmacological approach is recommended to be used prior to or in conjunction with sedatives use. Listening to Holy Quran Recitation (HQR) is a kind of spiritual support for Muslim patients. Spiritual care has been recommended as it can affect patient's comfort. Accordingly, spiritual support strategies including HQR have been recently proposed to achieve better outcomes of critically ill patients which is the aim of the current study. Methods: A quasi experimental research design was used in this study. Physiological and psychological parameters were measured before and after HQR in the study group. Results: All differences between physiological and psychological parameters of the study group before and after $\mathrm{HQR}$ were statistically significant $(\mathrm{P}=0.00)$. All differences between initial and the final measurement values of physiological and psychological parameters of the control group were statistically not significant. The mean values of heart rate, respiratory rate, mean arterial blood pressure, and shortness of breath of the study group after HQR were lower than that in the control group. $\underline{\text { Conclusion: } \mathrm{HQR}}$ is an effective non-pharmacological strategy to improve vital signs, $\mathrm{SpO}_{2}$, shortness of breath and anxiety level for mechanically ventilated Muslim patients undergoing weaning. In addition, it can increase spontaneous breathing trial (SBT) duration for patients undergoing weaning from MV.
\end{abstract}

Keywords: Mechanically ventilated patients, Weaning, Spontaneous breathing trail, Non-pharmacological management, Spiritual care, Holy Quran Recitation, Physiological parameters, Psychological parameters.

\section{Introduction}

Mechanical ventilation (MV) is a life-saving intervention for patients suffering from acute respiratory problems. The primary goal of MV is to help in gas exchange of the lungs until respiratory issues improve ${ }^{[1]}$. In spite of the fact that it is life-saving intervention, it is viewed as distressing ${ }^{[2,3]}$. Critically ill patients experience many stressors associated with their physiological condition, treatments, and the ICU surroundings itself $f^{[4]}$. Mechanically ventilated patients continuously experience psychological consequences from pain, agitation, and being unable to communicate, relax, or sleep ${ }^{[5-9]}$. Anxiety is considered as one of psychological outcomes of MV. An increased work of breathing and fatigue may result from inappropriately managed anxiety. These could result in a delay in patients' weaning ${ }^{[10]}$. After restoration of the respiratory problems, they can be weaned from
MV. Weaning is "a gradual decrease in ventilator settings that ends with termination of MV support" ${ }^{\text {[3] }}$. It represents a major challenge in critically ill patients' management ${ }^{[11]}$. Early assessment of weaning readiness from the first day of initiating MV is ought to lessen its duration consequently reducing the associated complications $^{[12,13]}$. Weaning from MV imposes more stress on the patients as it leads to feeling of helplessness ${ }^{[14,15]}$. Cardiovascular instability, prolongation of MV and ventilator associated pneumonia may also result from excessive and inappropriate use of sedatives ${ }^{[16]}$. Weaning may be associated with hemodynamic, respiratory and autonomic nervous system changes; tachypnea, tachycardia, systolic hypo or hypertension, arterial desaturation, sweating and anxiety. These changes are indicating weaning intolerance and weaning failure ${ }^{[17-20]}$.

Many interventions are needed during the duration of MV and weaning until extubation ${ }^{[21]}$. Critical care nurses have a significant 
role in relieving stress manifestations and supporting patients' holistic healing ${ }^{[22]}$. For that purpose, non-pharmacological approach is suggested to be used prior to the use of sedatives or in conjunction with them ${ }^{[14]}$. Listening to HQR is a kind of spiritual support for Muslim patients. Spiritual care has been recommended as it could have an effect on patient's comfort. It is a critical part of providing holistic nursing care ${ }^{[23]}$. Muslim believes every word in Al-Quran. The Prophet Muhammad peace be upon him (PBUH), for example, himself used and advised his followers to D'ua (prayer) in times of stress ${ }^{[24]}$. Several studies investigated the effect of HQR on ICU comatose patients' level of consciousness ${ }^{[25-27]}$. Findings of these studies showed that Quran sound can enhance comatose patients' level of consciousness. Some research examined the effect of HQR on vital signs ${ }^{[26-28]}$. The comparison of the mean values of systolic and diastolic blood pressure, heart rate and arterial oxygen pressure before and after HQR revealed significant differences. Mirzaeian and associates study findings were not significant for respiratory rate and body temperature ${ }^{[28]}$. Yadak et al. investigated the effect of listening to $\mathrm{HQR}$ on ICU patients undergoing weaning from MV. That pilot study findings depicted that there is no undesirable effect of HQR on ICU patients undergoing weaning ${ }^{[29]}$.

Ghiasi and Keramat carried out a systematic review of the effect of $\mathrm{HQR}$ listening on anxiety. The findings of this review revealed that there is a advantageous impact of HQR in reducing anxiety in a variety of settings including ICU ${ }^{[30]}$. Up to our knowledge, there is a limited number of clinical studies ${ }^{[31]}$ examining the effect of HQR on clinical outcomes for mechanical ventilated patients undergoing weaning which is the aim of the current study.

\section{Aim of the study}

This study aimed to evaluate the effect of HQR on clinical outcomes of patients undergoing weaning from MV.

\section{Operational definition}

Clinical Outcomes include physiological parameters; heart rate, mean arterial pressure, respiratory rate, $\mathrm{SpO}_{2}$ in addition to the shortness of breath and the duration of SBT and psychological parameter; anxiety level.

\section{Hypothesis}

Patients who listen to HQR have a lower heart rate, mean arterial pressure, respiratory rate than that of the control group.

Patients who listen to $\mathrm{HQR}$ have a higher $\mathrm{SpO}_{2}$ and a longer duration of SBT than that of the control group.

Patients who listen to HQR have a lower level of anxiety than that of the control group.

\section{Materials and Method}

3.1. Research design: A quasi- experimental research design was utilized to conduct this study.

3.2. Setting: This study was carried out in three general adult ICUs in a selected university hospital in Alexandria- Egypt. In which ICU policies and staff qualifications were almost the same.

3.3. Sample: All critically ill Muslim patients (69 patients) who were undergone weaning from MV in the previously mentioned ICUs from July 2017 to December 2018 were included in this study. The included patients were alert, free from delirium or hearing impairment, hemodynamically stable, mechanically ventilated for more than 4 days (long term mechanical ventilation), undergoing spontaneous breathing trials (SBTs). Patients were excluded from the study if they died, discharged or transferred from ICU throughout the 3 days of data collection. The final sample size was 60 patients. Patients were randomly assigned into either study or control groups (30 patients in each).

\subsection{Tools: Three tools were used for data collection \\ Tool I: Physiological parameters record}

This tool was developed by the researchers after reviewing the relevant literature to document the patients' physiological parameters before and after listening to $\mathrm{HQR}{ }^{[24,27,31]}$. It includes respiratory rate $(\mathrm{RR})$, heart rate $(\mathrm{HR})$, mean arterial pressure (MAP), and Peripheral Oxygen Saturation $\left(\mathrm{SpO}_{2}\right)$. Demographic and clinical data were also included e.g. age, sex, diagnosis, reason for intubation, duration of intubation, duration of MV, ICU length of stay, SBT duration.

\section{Tool II: Dyspnea visual analogue scale (DVAS)}

This tool was adopted for the use in this study to assess the severity of dyspnea reported by the studied patients. The DVAS is first described by Aitken in $1969^{[32]}$ to assess severity of dyspnea. The visual analogue scale consists of a $20 \mathrm{~cm}$ horizontal or vertical line' with bipolar opposite descriptors "not at all breathless" (lower end $0 \%$ ) and "extremely breathless" (upper end 100\%). The reliability of this scale was tested in many other research studies ${ }^{[32-35]}$. Tool II inter-rater reliability was done. It was 0.85 .

\section{Tool III: Visual Analogue Scale of Anxiety (VASA)}

This tool was adopted to be used in this study to assess the severity of anxiety reported by the studied patients. It is composed of 10 $\mathrm{Cm}$ line in length with (not at all anxious) and (very anxious) at the left and right extremes respectively. A mark near the center would indicate moderate anxiety. Tool reliability was tested in a research study before ${ }^{[36]}$. Tool III inter-rater reliability was done. It was 0.95 .

\subsection{Data collection}

This study was conducted in the previously mentioned ICUs after obtaining permission from hospital responsible authorities. Tool (I) was developed by the researchers based on extensive review of recent relevant literature ${ }^{[24,27,31]}$. Tool (II \& III) were adopted and translated into Arabic language. Tools were tested for content validity by a jury of five experts in the study field and the final form was finalized after proving validity. Internal consistency was used for tool I, it was 0.82 . For Tool II \& III, inter-rater reliability was done. They were 0.85 and 0.95 respectively. The results were statistically acceptable.

A pilot study was carried out on 6 patients (excluded from the study sample) from the previously mentioned settings to assess feasibility, clarity and applicability of the study tools. The present study was implemented in three phases (assessment, implementation and evaluation phase). Patients who undergone SBT for weaning were assigned into two groups either study or control groups. Demographic and clinical data were obtained from patients' record.

\section{Phase one: Assessment phase (Before SBT and intervention)}

Patients in both groups were assessed just before SBT for the physiological parameters (heart rate, mean arterial pressure, respiratory rate, $\mathrm{SpO}_{2}$, and shortness of breath. Values were recorded as baseline. In addition, anxiety level was also assessed and recorded.

Phase two: Implementation phase (during SBT and intervention) 


\section{a. Study group}

Patients were listened to Surat Al-Fatiha and Al-Baqara via noise free MP3 headphone for 30-minute 3 consecutive days. During the 30 minutes, physiological parameters, anxiety level, and shortness of breath were measured three times at five, fifteen and thirty minutes.

\section{b. Control group}

A noise free headphone was applied to those patients for 30 minutes for 3 consecutive days. During the 30 minutes, physiological parameters, and anxiety level were also measured three times at five, fifteen and thirty minutes of headphone application.

\section{Phase three: Evaluation phase (after intervention)}

Patients in both groups were evaluated for the physiological parameters, and anxiety level after intervention. Duration of SBT was measured daily in minutes for both groups.

\subsection{Ethical considerations}

The current study was approved by the research ethics committee of the faculty of nursing, Alexandria University, Egypt. Participation in this study was voluntary. Participants were informed of their right to withdraw from the study at any time. An informed consent was obtained from each of the included patients after explaining the aim of this study. Patients' confidentiality, anonymity, and privacy were ensured during the study.

\section{Data analysis}

First, descriptive statistical analysis for all study variables was conducted. Second, researchers performed comparisons between independent mean scores using independent sample t-test (for continuous variables), paired t-test (for continuous variables) before and after intervention in the same group, and Chi-square (for categorical variables). All statistics were conducted using SPSS version 25. All reported $\mathrm{p}$ values are two tailed and the 0.05 level was used to test statistical significance

\section{Results}

Figure 1 and 2 display the sex and age distribution of the recruited patients. It was found that $53.3 \%$ of the study group were males compared to $83.3 \%$ in the control group. It was also found that the most common age for the studied patients in the study group ranged from $>30-<40$ years $(40 \%)$, whereas the most common age group for patients in the control group was $>40-<50$ years $(40 \%)$.

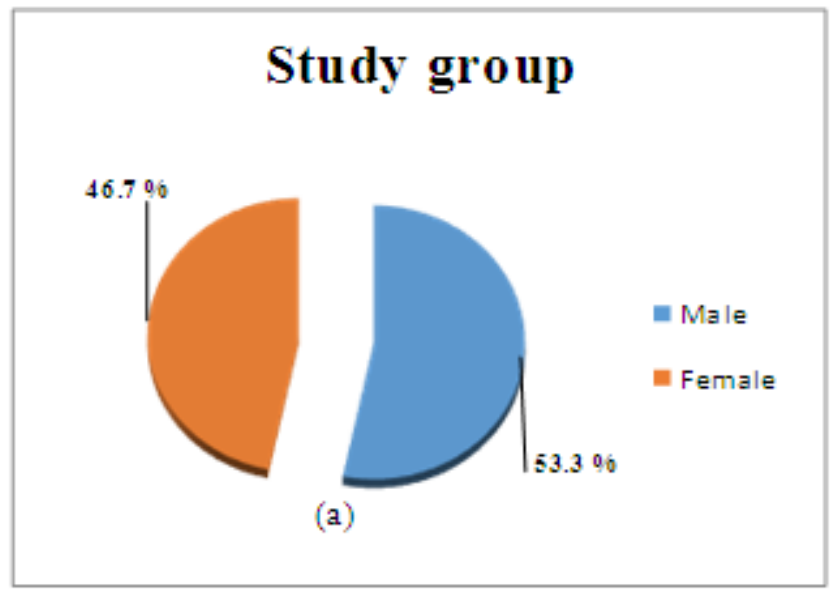

\section{Control group}

$16.7 \%$

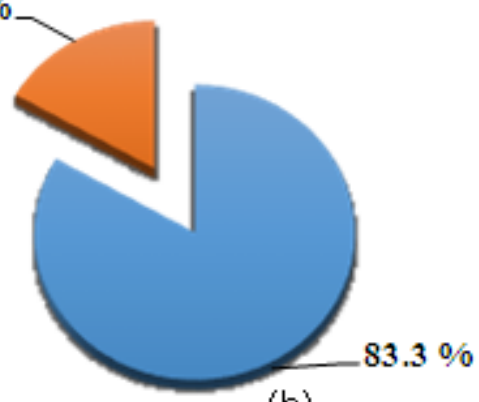

(b)

Figure 1: Frequency distribution of sex in the study and control groups

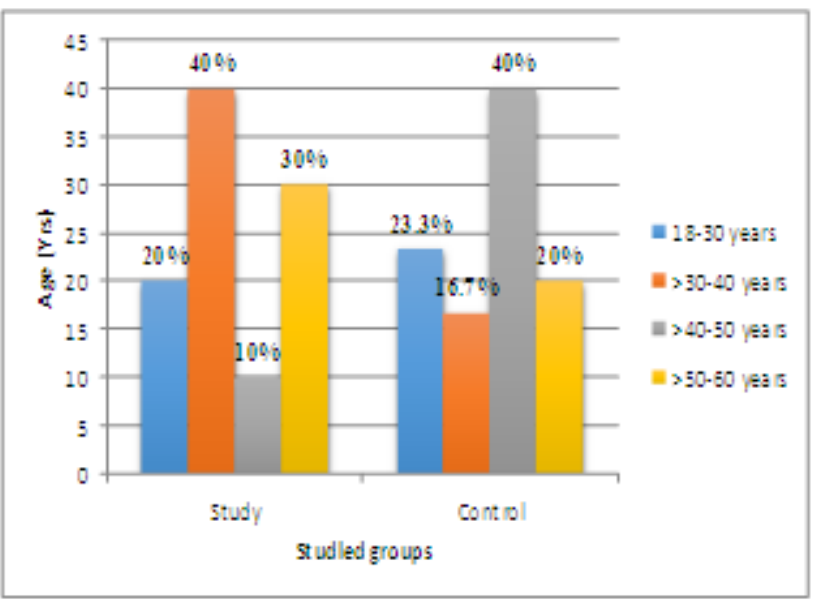

Figure 2: Frequency distribution of age in study and control groups

Table I illustrates distribution of the studied groups according to patients' clinical characteristics. The mean value of APACHE II score of the study group was $10.7 \pm 5.9$ compared to $9.9 \pm 8.2$ in the control group. A $20 \%$ of the studied patients in the study group had two or more co-morbidities compared to $26.7 \%$ in the control group. $60 \%$ of the studied patients in the study group compared to $46.7 \%$ of the control group were intubated to maintain ventilation. A $46.7 \%$ of the patients in the study group compared to $63.3 \%$ of the control group had an endotracheal tube sized $>7.5$. The mean duration of intubation in the study group was $79.7 \pm 45.3$ hours compared to $97.3 \pm 38.3$ hours in the control group. A $70 \%$ of the studied patients in the study group compared to $43.3 \%$ of the control group were mechanically ventilated for less than 72 hours. Differences between the study and the control group were not significant. The ICU length of stay after extubation was significantly higher in the control group than in the study group $(\mathrm{p}=0.00)$. 
Table I: Distribution of the studied groups according to patients' clinical characteristics

\begin{tabular}{|c|c|c|c|c|}
\hline \multicolumn{2}{|c|}{ Patients' clinical characteristics } & Study $(n=30)$ & Control $(n=30)$ & Test $(P)$ \\
\hline \multicolumn{2}{|c|}{$\begin{array}{l}\text { APACHE II score } \\
(\text { mean } \pm \text { SD })\end{array}$} & $10.7 \pm 5.9$ & $9.9 \pm 8.2$ & $\begin{array}{l}\mathrm{t}=2.16 \\
P=0.679\end{array}$ \\
\hline \multirow[t]{3}{*}{ Number of co-morbidities } & None & $14(46.7 \%)$ & $11(36.7 \%)$ & \multirow{3}{*}{$\begin{array}{l}X^{2}=3.1 \\
P=0.212\end{array}$} \\
\hline & One & $10(33.3 \%)$ & $11(36.7 \%)$ & \\
\hline & $\geq$ two & $6(20 \%)$ & $8(26.7 \%)$ & \\
\hline \multirow[t]{2}{*}{ Indication for intubation } & Oxygenation & $12(40 \%)$ & $16(53.3 \%)$ & \multirow{2}{*}{$\begin{array}{l}\mathrm{X}^{2}=0.267 \\
P=0.606\end{array}$} \\
\hline & Ventilation & $18(60 \%)$ & $14(46.7 \%)$ & \\
\hline \multirow[t]{2}{*}{ Size of ETT } & $\leq 7.5$ & $16(53.3 \%)$ & $11(36.7 \%)$ & \multirow{2}{*}{$\begin{array}{l}\mathrm{X}^{2}=1.684 \\
P=0.194\end{array}$} \\
\hline & $>7.5$ & $14(46.7 \%)$ & $19(63.3 \%)$ & \\
\hline \multicolumn{2}{|l|}{ Duration of intubation (hrs) } & $79.7 \pm 45.3$ & $97.3 \pm 38.3$ & $\begin{array}{l}\mathrm{t}=1.62 \\
P=0.112\end{array}$ \\
\hline \multirow[t]{2}{*}{ Duration of MV } & $\leq 72$ hours & $21(70 \%)$ & $13(43.3 \%)$ & \multirow{2}{*}{$\begin{array}{l}\mathrm{X}^{2}=1.06 \\
P=0.302\end{array}$} \\
\hline & $>72$ hours & $9(30 \%)$ & $17(56.7 \%)$ & \\
\hline \multicolumn{2}{|l|}{ ICU length of stay (days) } & $7.7 \pm 5.0$ & $15.46 \pm 8.5$ & $\begin{array}{l}\mathrm{t}=4.313 \\
P=0.00^{*}\end{array}$ \\
\hline
\end{tabular}

APACHE: Acute physiology and clinical health evaluation, SBTs: Spontaneous breathing trials,

MV: Mechanical Ventilation hrs: hours $P$ Significant at $\leq 0.05$

Table II shows the studied groups distribution according to the mean values of physiological and psychological parameters before and after intervention. Regarding the physiological parameters, it was found that the mean values of heart rate, respiratory rate, MAP, and shortness of breath of the study group after HQR were $(69.3 \pm 0.73,13.86 \pm 2.4,82.38 \pm 4.7$, and $0.13 \pm 0.3$ respectively) which were lower than the mean values before HQR $(82.8 \pm 1.07$, $20.16 \pm 2.8,90.88 \pm 7.2$, and $5.83 \pm 1.20$ respectively). The mean value of $\mathrm{SpO}_{2}$ in the study group after HQR was $(97.3 \pm 0.8)$ which was higher than that $(96.4 \pm 1.3)$ before HQR. Concerning the psychological parameter; this table depicts that; the mean anxiety score of the study group after HQR was $(0.5 \pm 0.6)$ which was lower than that $(5.86 \pm 1.19)$ before HQR. All differences between physiological and psychological parameters of the study group before and after HQR were statistically significant $(\mathrm{P}=0.00)$.

This table also shows that the mean values of heart rate and MAP of the control group post intervention were $(88.1 \pm 5.1$ and $94.04 \pm 4.25$ respectively) which were higher than these before intervention $(86.1 \pm 7.6$ and $87.01 \pm 5.16$ respectively). The mean score of anxiety after intervention was $3.16 \pm 1.01$ which was higher than that $(3.10 \pm 0.7)$ before intervention. All differences between the values before and after intervention in physiological and psychological parameters of the control group were not statistically significant.

Table II: Distribution of the studied groups according to the mean values of physiological and psychological parameters before and after intervention

\begin{tabular}{|c|c|c|c|c|c|}
\hline \multirow{2}{*}{\multicolumn{2}{|c|}{ Measured parameters }} & \multirow{2}{*}{\multicolumn{2}{|c|}{ Study group $(\mathrm{no}=30)$}} & \multirow{2}{*}{\multicolumn{2}{|c|}{ Control group $(\mathrm{no}=\mathbf{3 0})$}} \\
\hline & & & & & \\
\hline \multirow[t]{10}{*}{ Physiological parameters } & HR & $\begin{array}{l}\text { Before intervention } \\
\text { Mean } \pm \text { SD } \\
82.8 \pm 1.07\end{array}$ & $\begin{array}{l}\text { After intervention } \\
\text { Mean } \pm \text { SD } \\
69.3 \pm 0.73\end{array}$ & $\begin{array}{l}\text { Before intervention } \\
\text { Mean } \pm \text { SD } \\
86.1 \pm 7.6\end{array}$ & $\begin{array}{l}\text { After intervention } \\
\text { Mean } \pm \text { SD } \\
88.1 \pm 5.1\end{array}$ \\
\hline & t-test $(P)$ & \multicolumn{2}{|l|}{$12.3(0.00)$} & \multicolumn{2}{|l|}{$-1.68(0.102)$} \\
\hline & RR & $20.16 \pm 2.8$ & $13.86 \pm 2.4$ & $21.5 \pm 2.3$ & $20.63 \pm 1.4$ \\
\hline & t-test $(P)$ & \multicolumn{2}{|l|}{$13.5(0.00)$} & \multicolumn{2}{|l|}{$2.00(0.074)$} \\
\hline & MAP & $90.88 \pm 7.2$ & $82.38 \pm 4.7$ & $87.01 \pm 5.16$ & $94.04 \pm 4.25$ \\
\hline & t-test $(P)$ & \multicolumn{2}{|l|}{$7.28(0.00)$} & \multicolumn{2}{|l|}{$0.684(0.5)$} \\
\hline & $\mathrm{SpO}_{2}$ & $96.4 \pm 1.3$ & $97.3 \pm 0.8$ & $97.36 \pm 0.8$ & $97.36 \pm 0.8$ \\
\hline & t-test $(P)$ & \multicolumn{2}{|l|}{$-4.5(0.00)$} & \multicolumn{2}{|l|}{-} \\
\hline & SOB* & $5.83 \pm 1.20$ & $0.13 \pm 0.3$ & $5.67 \pm 1.63$ & $5.67 \pm 1.63$ \\
\hline & t-test $(P)$ & \multicolumn{2}{|l|}{$26.4(0.00)$} & \multicolumn{2}{|l|}{-} \\
\hline \multirow[t]{2}{*}{ Psychological parameter } & Anxiety score & $5.86 \pm 1.19$ & $0.5 \pm 0.6$ & $3.10 \pm 0.7$ & $3.16 \pm 1.01$ \\
\hline & t-test $(P)$ & \multicolumn{2}{|l|}{$23.4(0.00)$} & \multicolumn{2}{|l|}{$-0.40(0.69)$} \\
\hline
\end{tabular}

\section{$* P$ Significant at $\leq 0.05$}

Table III: shows the distribution of the studied groups according to the mean values of physiological and psychological parameter post intervention. This table illustrates that the mean values of HR, RR, MAP, and SOB in the study group after HQR are $(69.3 \pm 0.73$, $13.86 \pm 2.4,82.38 \pm 4.7$, and $0.13 \pm 0.3$ respectively). These are lower than the mean values in the control group after internvention $(88.1 \pm 5.1, \quad 20.63 \pm 1.4, \quad 94.04 \pm 4.25, \quad 5.67 \pm 1.63$ respectively). Differences between the study and the control group after intervention were statistically significant $(\mathrm{P}=0.00)$.

These findings support the study hypotheses which propose that, patients who listen to HQR have a lower HR, RR, and RR than that of the control group, patients who listen to HQR have a higher $\mathrm{SpO}_{2}$ control group. Concerning psychological parameter between the study and the control group at the final measurement, this table also depicts that, the mean anxiety score at the final measurement of the study group is $(0.5 \pm 0.6)$. It is lower than that for the control group $(3.16 \pm 1.01)$. The difference between the study and the control group at the final measurement is statistically significant $(\mathrm{P}=0.00)$.This finding supports the study hypothesis which proposes that, patients who listen to HQR have a lower level of anxiety than that of the control group. 
Table III: Distribution of the Studied groups according to the mean values of physiological and psychological parameter after intervention

\begin{tabular}{|l|l|l|l|l|}
\hline Measured parameters & $\begin{array}{l}\text { Study group } \\
\text { no= 30 }\end{array}$ & $\begin{array}{l}\text { Control group } \\
\text { no= 30 }\end{array}$ & $\begin{array}{l}\text { Test of significance } \\
(\boldsymbol{P})\end{array}$ \\
\cline { 3 - 5 } & $\begin{array}{l}\text { After intervention } \\
\text { Mean } \pm \text { SD }\end{array}$ & $\begin{array}{l}\text { After intervention } \\
\text { Mean } \pm \text { SD }\end{array}$ & \\
\hline \multirow{3}{*}{ Physiological parameters } & HR & $69.3 \pm 0.73$ & $88.1 \pm 5.1$ & $15.7(0.00)$ \\
\cline { 2 - 5 } & RR & $13.86 \pm 2.4$ & $20.63 \pm 1.4$ & $13.3(0.00)$ \\
\cline { 2 - 5 } & MAP & $82.38 \pm 4.7$ & $94.04 \pm 4.25$ & $-4.9(0.00)$ \\
\cline { 2 - 5 } & SPO 2 & $97.3 \pm 0.8$ & $97.36 \pm 0.8$ & $14.1(0 . .00)$ \\
\cline { 2 - 5 } & SOB & $0.13 \pm 0.3$ & $5.67 \pm 1.63$ & $11.6(0.00)$ \\
\hline Psychological parameter & Anxiety score & $0.5 \pm 0.6$ & $3.16 \pm 1.01$ & $10.09(0.00)$ \\
\hline
\end{tabular}

* SOB: Shortness of Breath P Significant at $\leq 0.05$ HR heart rate RR respiratory rate

MAP mean arterial pressure $\mathrm{SpO}_{2}$ oxygen saturation

Table IV depicts the comparison between the studied groups regarding SBT duration. The SBT duration increased significantly in the study group compared to that in the control group during the first, second and third day of data collection $(\mathrm{P}=0.00)$. This finding

Table IV: Comparison the studied groups regarding SBT duration

\begin{tabular}{|l|l|l|l|}
\hline SBT duration $($ hrs. $)$ & Study group $($ no= 30$)$ & Control group $($ no $=30)$ & t- test $(P)$ \\
\hline $1^{\text {st }}$ trial & $36.83 \pm 12.89$ & $27 \pm 7.49$ & $3.61(0.00)$ \\
\hline $2^{\text {nd }}$ trial & $46.16 \pm 14.60$ & $21 \pm 14.76$ & $6.41(0.00)$ \\
\hline $3^{\text {rd }}$ trial & $53.66 \pm 13.38$ & $14.16 \pm 17.57$ & $9.79(0.00)$ \\
\hline
\end{tabular}

\section{Discussion}

Nurses have an important role in patient care as they stay 24 hours a day with the patient. Non-pharmacological management is suggested by many studies especially the approach which is focusing on spiritual care ${ }^{[23,25-31]}$. The aim of this study was to examine the effect of HQR on clinical outcomes of long term mechanically ventilated patients undergoing SBTs.

This study findings show that there was a statistically significant differences between the studied groups regarding HR, MAP and $\mathrm{SpO}_{2}$ after intervention. This may be due to the effect of Quran sounds which leads to spiritual relaxation and reducing stress imposed by weaning process and improving physiological parameters of the body. These findings are in line with Nasiri et al., El-Hady \& Kandeel; and Mirzaeian et al studies ${ }^{[26-28]}$ which concluded that HQR affected vital sings significantly. There was also a significant difference between the studied groups regarding respiratory rate after intervention which is incongruent with Yadak respiratory rate or body temperature.

Moreover, anxiety mean values reduced significantly after HQR in the study group compared to that in the control group. This is also may be related to the spiritual relaxation which occurs from the sound waves of Quran. These findings are in line with Ghiasi et al. systemic review conclusions which revealed that there is a positive effect of HQR in reducing anxiety in a variety of settings including ICU ${ }^{[30]}$. This study results also consistent with Najafi et al study which examined the effect of HQR and aromatherapy in seventy acute myocardial infarction patients. Their study depicted a statistical difference in the Spielberg anxiety questionnaire mean score between the studied groups after intervention ${ }^{[37]}$.

Regarding SBT durations, this study concluded that the mean SBT durations increased significantly in the 3 days of data collection in the study group compared to the control group. On the other side, a study conducted by Liang et al reported that RR and Dyspnea VAS et al. study result ${ }^{[29]}$ which revealed that HQR did not affect supports the study hypothesis which proposes that, patients who listen to HQR have a longer duration of SBT than that of the control group. decreased significantly by listening to music which is another kind of non-pharmacological intervention. That study also concluded the daily weaning trials duration increased ${ }^{[38]}$.

\subsection{Implications to practice}

- Using non- pharmacological interventions during weaning from MV is desirable.

- $\quad$ The HQR is a simple, low cost strategy and preferably suited for Muslim patients in ICU as it can reduce stressimposed by ICU including the weaning process.

\subsection{Limitations of the study}

Small sample size might limit the generalization of the study. Moreover, only one reciter was offered to the patients. Patients did not have an option to choose which Surah or which reciter voice are preferred.

\section{Conclusion and Recommendations}

$\mathrm{HQR}$ is an effective non-pharmacological strategy to improve vital signs, $\mathrm{SpO}_{2}$, shortness of breath and anxiety level for mechanically ventilated Muslim patients. In addition, it can increase SBT duration for patients undergoing weaning from MV.

Nurses should assess patients' spiritual needs and the need for specific spiritual intervention "HQR" during weaning from MV. Nurses can offer HQR to Muslim patients during weaning from MV.

Further research is needed to investigate the comparison of different reciter sounds and different Surah

\section{Acknowledgement}

Authors of this study would like to thank the staff of Critical Care Medicine department in Alexandria University, Egypt especially, Prof. Dr. Mohamed Megahed for his cooperation during data 
collection process. Authors also would like to thank the ICU nursing staff in Alexandria Main University hospital for their cooperation during the study.

\section{References}

[1] Engstrom, A., et al., People's experiences of being mechanically ventilated in an ICU: a qualitative study. Intensive Crit Care Nurs, 2013. 29(2): p. 88-95.

[2] Chlan, L.L., W.C. Engeland, and K. Savik, Does music influence stress in mechanically ventilated patients? Intensive \& critical care nursing, 2013. 29(3): p. 121127.

[3] Hetland, B., R. Lindquist, and L.L. Chlan, The influence of music during mechanical ventilation and weaning from mechanical ventilation: A review. Heart \& lung: the journal of critical care, 2015. 44(5): p. 416-425.

[4] Gültekin, Y., et al., Evaluation of stressors in intensive care units. Turkish journal of surgery, 2018. 34(1): p. 58.

[5] Chlan, L.L., et al., Effects of patient-directed music intervention on anxiety and sedative exposure in critically ill patients receiving mechanical ventilatory support: a randomized clinical trial. Jama, 2013. 309(22): p. 2335-2344.

[6] Rose, L., et al., Psychological wellbeing, health related quality of life and memories of intensive care and a specialised weaning centre reported by survivors of prolonged mechanical ventilation. Intensive and Critical Care Nursing, 2014. 30(3): p. 145-151.

[7] Hetland, B., et al., Predictive Associations of Music, Anxiety, and Sedative Exposure on Mechanical Ventilation Weaning Trials. American journal of critical care: an official publication, American Association of Critical-Care Nurses, 2017. 26(3): p. 210-220.

[8] Engström, Å., et al., People's experiences of being mechanically ventilated in an ICU: A qualitative study. Intensive and Critical Care Nursing, 2013. 29(2): p. 8895.

[9] Aslani, Y., et al., An investigation of the psychological experiences of patients under mechanical ventilation following open heart surgery. ARYA atherosclerosis, 2017. 13(6): p. 274-281.

[10] Hunter, B.C., et al., Music therapy as an adjunctive treatment in the management of stress for patients being weaned from mechanical ventilation. J Music Ther, 2010. 47(3): p. 198-219.

[11] Amri, P., S. Zahra Mirshabani, and S. Hossein Ardehali, Weaning the Patient from the Mechanical Ventilator: A Review Article. Arch Crit Care Med, 2016. 1(4): p. e8363.

[12] Blackwood, B., et al., Protocolized versus nonprotocolized weaning for reducing the duration of mechanical ventilation in critically ill adult patients. Cochrane database of systematic reviews, 2014(11).

[13] Blackwood, B., et al., Use of weaning protocols for reducing duration of mechanical ventilation in critically ill adult patients: Cochrane systematic review and metaanalysis. BMJ, 2011. 342: p. c7237.

[14] Tracy, M.F. and L. Chlan, Nonpharmacological interventions to manage common symptoms in patients receiving mechanical ventilation. Crit Care Nurse, 2011. 31(3): p. 19-28.
[15] Saeed, A., I. Galal, and A. Shata, Evaluation of the psychological status of patients during and after weaning from mechanical ventilation. Egyptian Journal of Bronchology, 2014. 8(2): p. 160-166.

[16] Grap, M.J., et al., Sedation in adults receiving mechanical ventilation: physiological and comfort outcomes. American journal of critical care: an official publication, American Association of Critical-Care Nurses, 2012. 21(3): p. e53-e64.

[17] Arcentales, A., et al., Classification of patients undergoing weaning from mechanical ventilation using the coherence between heart rate variability and respiratory flow signal. Physiol Meas, 2015. 36(7): p. 1439-52.

[18] Teboul, J.-L., X. Monnet, and C. Richard, Weaning failure of cardiac origin: recent advances. Critical care (London, England), 2010. 14(2): p. 211-211.

[19] Talwar, D. and V. Dogra, Weaning from mechanical ventilation in chronic obstructive pulmonary disease: Keys to success. The Journal of Association of Chest Physicians, 2016. 4(2): p. 43-49.

[20] Zein, H., et al., Ventilator Weaning and Spontaneous Breathing Trials; an Educational Review. Emerg (Tehran), 2016. 4(2): p. 65-71.

[21] Chlan, L.L., et al., Effects of Patient-Directed Music Intervention on Anxiety and Sedative Exposure in Critically Ill Patients Receiving Mechanical Ventilatory Support: A Randomized Clinical TrialPatient-Directed Music Intervention. JAMA, 2013. 309(22): p. 23352344.

[22] Cho, E.H., M.-Y. Lee, and M.-H. Hur, The Effects of Aromatherapy on Intensive Care Unit Patients' Stress and Sleep Quality: A Nonrandomised Controlled Trial. Evidence-based complementary and alternative medicine: eCAM, 2017. 2017: p. 2856592-2856592.

[23] Ramezani, M., et al., Spiritual care in nursing: a concept analysis. Int Nurs Rev, 2014. 61(2): p. 211-9.

[24] Abu Bakar, S. EFFECTS OF HOLY QURAN LISTENING ON PHYSIOLOGICAL STRESS RESPONSE AMONG MUSLIM PATIENTS IN INTENSIVE CARE UNIT. in Synergizing Knowledge on Management and Muamalah. 2014. Malysia.

[25] Naseri-Salahshour, V., et al., The effect of religious intervention on the level of consciousness of comatose patients hospitalized in an intensive care unit: a randomized clinical trial. European Journal of Integrative Medicine, 2018. 21: p. 53-57.

[26] Nasiri, A.A., H. Shahdadi, and A. Mansouri, An Investigation into the Effect of Listening to the Voice of the Holy Quran on Vital Signs and Consciousness Level of Patients Admitted to the ICU Wards of Zabol University of Medical Sciences Hospitals. World Family Medicine Journal/Middle East Journal of Family Medicine, 2017. 15(10): p. 75-79.

[27] El-Hady, M. and N. Kandeel, The Effect of Listening to Qur'an on Physiological Responses of Mechanically Ventilated Muslim Patients. IOSR Journal of Nursing and Health Science, 2017. 6(5): p. 79- 87.

[28] Mirzaeian, R., et al. THE EFFECT OF HOLY QURAN RECITATION SOUND ON VITAL SIGNS AND ARTERIAL OXYGEN PRESSURE OF UNCONSCIOUS PATIENTS HOSPITALIZED IN ICU. in Iajps,csk Publications. 2017. 
[29] Yadak, M., et al., The Effect of Listening to Holy Quran Recitation on Weaning Patients Receiving Mechanical Ventilation in the Intensive Care Unit: A Pilot Study. J Relig Health, 2019. 58(1): p. 64-73.

[30] Ghiasi, A. and A. Keramat, The Effect of Listening to Holy Quran Recitation on Anxiety: A Systematic Review. Iranian journal of nursing and midwifery research, 2018. 23(6): p. 411-420.

[31] Mat Nor, M.B., et al., Physiological and Psychological Effects of Listening To Holy Quran Recitation in the Intensive Care Unit Patients: A Systematic Review. Vol. 18. 2019. 145-155.

[32] de Torres, J.P., et al., Power of outcome measurements to detect clinically significant changes in pulmonary rehabilitation of patients with COPD. Chest, 2002. 121(4): p. 1092-8.

[33] Society, A.T., Dyspnea. Mechanisms, assessment, and management: a consensus statement. American Thoracic Society. Am J Respir Crit Care Med, 1999. 159(1): p. 321-40.

[34] Crisafulli, E. and E.M. Clini, Measures of dyspnea in pulmonary rehabilitation. Multidisciplinary Respiratory Medicine, 2010. 5(3): p. 202.

[35] Eaton, T., et al., Ambulatory oxygen improves quality of life of COPD patients: a randomised controlled study. European Respiratory Journal, 2002. 20(2): p. 306.
[36] Facco, E., et al., Validation of visual analogue scale for anxiety (VAS-A) in preanesthesia evaluation. Minerva Anestesiol, 2013. 79(12): p. 1389-95.

[37] Najafi, Z., The effect of simultaneous aromatherapy and Quran recitation on anxiety level of patients with myocardial infarction. 2014.

[38] Liang, Z., et al., Music intervention during daily weaning trials-A 6 day prospective randomized crossover trial. Complement Ther Med, 2016. 29: p. 72-77.

\section{Author Profile}

Nermine Elcokany received B.Sc., M.Sc., PhD degrees in Nursing from Faculty of Nursing, Alexandria University in 2003, 2008, and 2014, respectively. In a period from the beginning of 2012 to the end of 2013, a pre-doctoral fellowship in School of Nursing, Pitt University, USA. Now, she is a lecturer of Critical Care \& Emergency Nursing, in Faculty of Nursing, Alexandria, Egypt.

Mona Saad Abd El Wareth received B.Sc., M.Sc., PhD degrees in Nursing from Faculty of Nursing, Alexandria University in 2002, 2007, and 2012, respectively. Now, she is a lecturer of Critical Care \& Emergency Nursing, in Faculty of Nursing, Alexandria, Egypt. 